\title{
Industrijsko sušenje rezane građe: eksperiment i matematičko modelovanje kinetike sušenja
}

S irovo drvo sadrži znatne količine vode/vlage u sebi, i to da sadržaj vode može da se kreće u granicama od 40 do preko $200 \%$ u odnosu na suvu drvnu materiju u zavisnosti od vrste drveta i dela stabla [1]. Da bi se oboreno i prerađeno drvo moglo upotrebiti za izradu finalnih proizvoda zadovoljavajućeg kvaliteta, neophodno je da ima odgovarajuću vlažnost, odnosno potrebno je smanjiti sadržaj vode u njemu, što se postiže sušenjem. Prisustvo vode $u$ većim količinama stvara povoljne uslove za razvoj mikroorganizama koji razaraju drvo, utiče na promene dimenzija, smanjuje kvalitet drveta usled pojava pufkotina, vitoperenja i krivljenja, smanjuje ili onemogućuje sposobnost slepljivanja, isključuje mogućnost površinske obrade drveta, odnosno, ima niz negativnih posledica, uključujući i veću težinu proizvoda, što poskupljuje transport [1-4].

\section{1}

TEORIJSKI DEO

\section{$1.1 \quad$ Uvod}

Osnovni činioci koji uslovljavaju sušenje drveta su: temperatura i vlažnost vazduha, vazdušni pritisak i kretanje ili cirkulacija vazduha. To su spoljni faktori koji utiču na veoma složene procese kretanje vode u drvetu, koji zavise i od smera drvnih vlakanaca, građe drveta i dr $[1,2,5]$. Razlikuju se tri načina kretanja vlage u drvetu i to: kretanje vlage iznad granice higroskopnosti, kretanje vodene pare ispod granice higroskopnosti i kretanje higroskopski vezane vlage. U toku procesa sušenja vlaga se može kretati u sva tri navedena vida istovremeno [3].

Drvo se može sušiti prirodno i veštački, odnosno u posebno konstruisanim sušarama, gde je moguća potpuna regulacija i kontrola stanja, odnosno, parametara vlažnog vazduha [1-4]. Veštačko sušenje drveta, koje se široko primenjuje u drvnoj industriji, u odnosu na prirodno sušenje, obezbeđuje standardni kvalitet gotovih proizvoda, daje mogućnost postizanja nižeg sadržaja vlage, omogućava skraćenje trajanja procesa sušenja do željenog procenta vlage od nekoliko godina ili meseci, kod prirodnog sušenja, na nekoliko dana ili časova, kod veštačkog sušenja, smanjenje potrebnog prostora za uskladištenje rezane građe, smanjenje mogućnosti od napada insekata i gljiva i daje mogućnost postizanja većeg obrta kapitala [3]. Međutim, u oba slučaja sušenja osnovni faktori sušenja su isti. Takođe, i u prirodnom i u veštačkom načinu sušenja drveta toplim vazduhom primenjuje se slaganje drveta u složaj, odvajanje redova letvicama, oblikovanje složaja, odnosno određena tehnika sušenja [2-4].
Sušenje drveta toplim vazduhom u sušarama je najviše primenjivan način sušenja u proizvodnji finalnih proizvoda od drveta, dok se drugi načini (sušenje u vakuumu, sušenje visokofrekventnom strujom, hemijsko sušenje i dr.) imaju manju industrijsku primenu [3].

Ispitivanje uticaja procesnih parametara (relativna vlažnost, temperatura) vlažnog vazduha i praćenje njihovih vrednosti, pod nekim režimom sušenja, ima za cilj da se proces sušenja obavi za što kraće vreme, sa što je moguće manjim utrošcima energije, a da se s druge strane održi odgovarajući kvalitet osušenog drveta.

Cilj ovog rada bio je ispitivanje procesa sušenja drvene građe $u$ industrijskim uslovima. Materijal za ovaj rad dobijen je iz preduzeća za proizvodnju laminata i parketa, u čijim pogonima su izvedeni eksperimenti. Sušenje do nekog finalnog sadržaja vlage, potrebnog za dobijanje gotovog proizvoda, izvođeno je u industrijskoj, automatskoj, klasičnoj konvektivnoj sušari, italijanskog proizvođača "Incomac" [6, 7].

Određivane su krive sušenja i brzine sušenja za daske različitih dimenzija, i praćen raspored vlažnosti u daskama tokom sušenja. Dobijeni eksperimentalni rezultati modelovani su sa nekoliko najznačajnijih empirijskih matematičkih modela koji se primenjuju za opisivanje sušenja drveta $[8,9]$.

\subsection{MATEMATIČKI MODELI SUŠENJA DRVETA}

Matematički modeli kojima se u literaturi opisuje proces sušenja mogu biti difuzioni, numerički i/ili empirijski [8], pri čemu je u ovom radu ispitana primenljivost 5 empirijskih modela za matematičko modelovanje kinetike sušenja rezane hrastove građe.

Procena brzine sušenja je veoma korisna za razumevanje mehanizma kretanja vlage $u$ drvetu i transporta vlage sa drveta u okolni vazduh. Kriva brzine sušenja se dobija grafičkim diferenciranjem tačaka duž krive sušenja (sadržaj vlage u funkciji vremena) i ucrtavanjem na grafiku prvog izvoda (nagiba tangenti) za odgovarajuće sadržaje vlage u materijalu. U idealnom slučaju, kriva sušenja može se opisati jednačinom koja se može diferencirati i dobiti kriva brzine sušenja.

Jednačine različitog oblika mogu se koristiti za opisivanje sušenja drveta. Do sada su u tu svrhu korišćene logaritamska/eksponencijalna, linearna i polinomska funkcija.

Jedan krajnje jednostavan, ali koristan pristup određivanju brzine sušenja je pretpostaviti da je brzina sušenja proporcionalna srednjem sadržaju vlage u toku perioda opadajuće brzine sušenja. Ovo se 
matematički opisuje izrazom:

$$
\frac{d M}{d t}=-k \cdot M
$$

$$
\begin{aligned}
& \text { gde su: } \\
& \text { M - sadržaj vlage (kg vlage / kg suvog dela materijala), } \\
& \text { t - vreme i } \\
& \text { k - empirijska konstanta. }
\end{aligned}
$$

Ovo je diferencijalna jednačina, čije je rešenje:

$$
M=M_{0} \cdot \exp (-k t)
$$

Ako se leva strana jednačine (2) definiše kao relativni sadržaj vlage, MR, jednačina postaje:

$$
M R=\frac{M-M_{r}}{M_{0}-M_{r}}=\exp \left(-k_{1} \cdot t\right)
$$

gde su:

$\mathrm{M}_{\mathrm{r}}$ - ravnotežni sadržaj vlage i

$\mathrm{M}_{0}$ - početni sadržaj vlage.

Ravnotežni sadržaj vlage, $\mathrm{M}_{\mathrm{r}}$, funkcija je temperature i relativne vlažnosti vazduha kojim se suši drvo. Vrednosti $M_{r}$ su procenjene na osnovu parametra $\mathrm{E}_{2}$ modela $\mathrm{M}=\mathrm{E}_{0} \bullet \exp \left(-\mathrm{E}_{1} \bullet \mathrm{t}+\mathrm{E}_{2}\right)$. Empirijska konstanta, $\mathrm{k}_{1}$, se eksperimentalno odrđuje regresionom analizom kao funkcija vrste drveta, geometrije materijala i spoljnih faktora (temperature, relativne vlažnosti i brzine vazduha).

Grafik zavisnosti relativnog sadržaja vlage u funkciji vremena sušenja nije linearna flunkcija. U nekim slučajevima transformacijom relativnog sadržaja vlage u logaritamsku skalu (prirodni logaritam) može se postići linearizacija.

Model koji se takođe može koristiti za opisivanje zavisnosti prirodnog logaritma relativnog sadržaja vlage od vremena sušenja glasi:

$$
M R=k_{2} \cdot \exp \left(-k_{3} \cdot t\right)
$$

gde su: $\mathrm{k}_{2} \mathrm{i} \mathrm{k}_{3}$ regresioni koeficijenti.

Ovaj prost eksponencijalni model dobijeni su pojednostavljenjem matematičkog rešenja drugog Fikovog zakona difuzije, koji ima oblik opštih redova. Prost eksponencijalni model je prvi član opšteg reda koji se dobija kao rešenje modela. On po svojoj prirodni dosledno prebacuje vrednošti brzine sušenja u početnom stadijumu sušenja i podbacuje vrednosti u kasnijem stepenu sušenja [8].

Model koji predlaže Page [8] je još jedna empirijska modifikacija prostog eksponencijalnog modela koja bi trebalo da prevaziđe njegove nedostatke. Page model je sledećeg oblika:

$$
M R=\exp \left(k_{4} \cdot t^{y}\right.
$$

gde su: $\mathrm{k}_{4} \mathrm{i}$ y parametri modela.
Polinomske zavisnosti su korišćene za opisivanje krivolinijskih zavisnosti sadržaja vlage od vremena sušenja [8, 10]. Mogu biti korišćeni modeli različitog stepena, pri čemu veličina stepena polinoma treba da bude statistički opravdana. U ovom radu je za opisivanje sušenja korišćen polinom drugog stepena:

$$
M=\beta_{0}+\beta_{1} \cdot t+\beta_{2} \cdot t^{2}
$$

gde su:

$\beta_{0}$ - odsečak,

$\beta_{1}, \beta_{2}$ - regresioni koeficijenti.

\section{EKSPERIMENTALNI DEO}

\subsection{Materijal}

Sirovo drvo korišćeno za eksperimente sušenja u ovom radu je hrast. Od navedenog sirovog drveta dobijena je rezana građa, koja je pre sušenja u sušari, sušena u spoljašnjim uslovima, prirodnim putem. Od raspoložive rezane građe namenjene izradi laminata i briketa, uzimani su uzorci, kontrolne daske, na slučajan način. Sušenje do nekog finalnog sadržaja vlage, potrebnog za dobijanje gotovog proizvoda, izvođeno je u industrijskoj, klasičnoj konvektivnoj sušari, italijanskog proizvođača "Incomac". Standardna građa je sušena u paletama. Prilikom formiranja složaja i pozicioniranja paleta ispoštovana su sva pravila, kako bi se obezbedila što je moguće veća kontaktna površina između medijuma za sušenje (vlažnog vazduha) i drveta, odnosno daske su postavljene tako da se obezbedi najbolje strujanje vazduha kroz složaj. Pogrešno postavljanje letvica i pogrešno postavljanje paleta doprinosi lošem kvalitetu piljene građe. U pogledu pozicije ventilatora, drvena građa je bila paralelno postavljena.

\subsection{Kontrolne daske}

U cilju praćenja promene vlažnosti materijala tokom sušenja, bilo zbog podešavanja parametara vlažnog vazduha, u slučaju kada poluautomatika nije opremljena daljinskim elektrovlagomerima, ili, kao što je to bio slučaj u ovom radu, u cilju izvođenja eksperimenta, u sušnicu se postavljaju kontrolne daske. Kontrolne daske treba u potpunosti da reprezentuje materijal koji se suši i to u pogledu: vrste drveta, debljine građe, početne vlažnosti, vrste sortimenata i kvaliteta građe. Broj kontrolnih dasaka zavisi od kapaciteta komore i od uređaja za vođenje procesa. U načelu sa povećanjem kapaciteta komore broj kontrolnih dasaka treba da bude veći. Broj mernih mesta obično se kreće od 3 do 12, zavisno od konstrukcije uređaja. U svakom slučaju veći broj kontrolnih dasaka obezbeđuje veću pouzdanost vođenja procesa sušenja i dobijanje kvalitetnije osušene piljene građe [3].

Izrezane kontrolne daske, uzorci, u ovim eksperimentima postavljeni su sa spoljašnje strane palete, kako bi bio omogućen lak pristup i njihovo vađenje iz komore, uz minimalno remećenje rada sušare i tako da u potpunosti "obuhvate" komoru. Nakon izvršenog merenja, kontrolne daske nisu bile vraćane u složaj.

Istraživanja su imala dva cilja od kojih je prvi bio ispitivanja rasporeda vlage $u$ drvenoj građi tokom sušenja (EKSPERIMENT - I), i praćenje kinetike sušenja za daske različitih dimenzija (EKSPERIMENT - II). Eksperimenti su rađeni istovremeno. 
Dimenzije uzoraka za dva eksperimenta bile su različite i iznosile su za: $230 \times 80 \times 25 \mathrm{~mm}$ (EKSPERIMENT- I) i $230 \times 80 \times 25 \mathrm{~mm}$ (EKSPERIMENT - II, serija 1), 180×80×25 mm (EKSPERIMENT - II, serija 2) i $130 \times 80 \times 25 \mathrm{~mm}$ (EKSPERIMENT - II, serija 3). Za EKSPERIMENT - I iskorišćeno je 10 kontrolnih dasaka. Za EKSPERIMENT - II za svaku od serija upotrebljeno je takođe po 10 kontrolnih dasaka.

Pre ubacivanja kontrolnih dasaka u sušaru izmerena im je masa. Takođe, uporedo je gravimetrijskom metodom i elektrovlagomerima na bazi električnog otpora određen je srednji sadržaj vlage u polaznom materijalu na osnovu merenja slučajno odabranih uzoraka.

Za EKSPERIMENT - I, na gornjoj površini kontrolnih dasaka iscrtavana je mreža (sa 15 polja - segmenata, obeleženih brojevima redom od 1 do 15), u cilju posmatranja rasporeda sadržaja vlage u pojedinim segmentima (Slika 1).

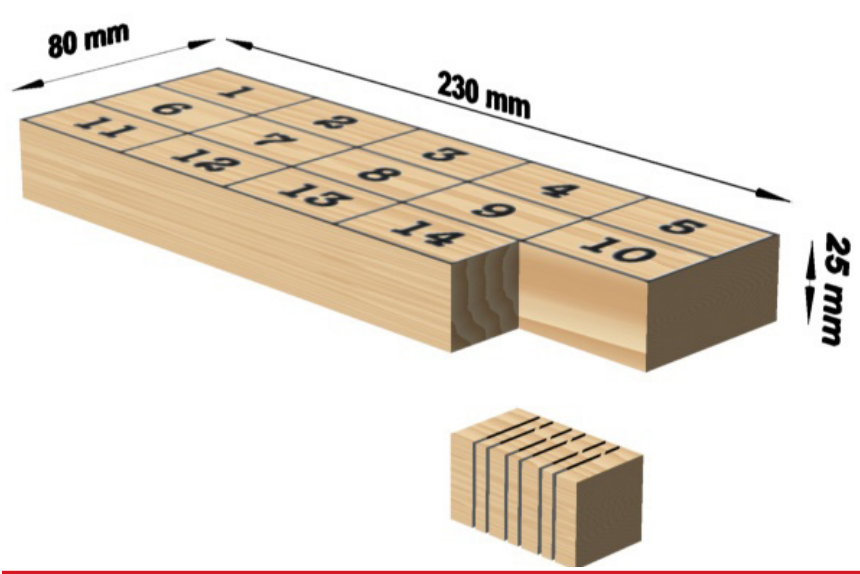

Slika 1: EKSPERIMENT - I; Kontrolna daska sa mrežom i njene dimenzije

Posle 24 časa prilagođavanja na uslove sušenja, na osnovu zadatih parametara režima sušenja (temperatura, relativna vlažnost vazduha) izvađena je jedna kontrolna daska za prvi eksperiment i po jedna kontrolna daska za svaku od tri serije drugog eksperimenta. Nakon merenja mase kontrolne daske na analitičkoj vagi, tačnosti $( \pm 0.001$ g) isecani su obeleženi segmenti iz kojih se uzimaju po tri male kontrolne probe (na način prikazan na slici gore) takođe isecanjem, i obeležavaju.

Vlažnost malih proba zatim se određuje standardnim gravimetrijskim postupkom. Odmah nakon izrezivanja, izmerena je masa proba pri tom stanju vlažnosti. Probe su zatim sušene u laboratorijskoj termostat sušnici na temperaturi od $103 \pm 2{ }^{\circ} \mathrm{C}$ do apsolutno suvog stanja. Izmerene su njihove mase u apsolutno suvom stanju. Na osnovu dobijenih podataka izračunavaju se vlažnosti malih proba.

EKSPERIMENT -II je vođen uporedo sa prvim tako da je sam početak eksperimenta isti i u ovom slučaju. Iz tri serije kontrolnih dasaka različitih dužina (Slika 2) na standardni način izrezivane su male kontrolne probe, merena je njihova masa pre i posle sušenja do apsolutno suvog stanja i na osnovu toga izračunat je sadržaj vlage svake kontrolne daske.

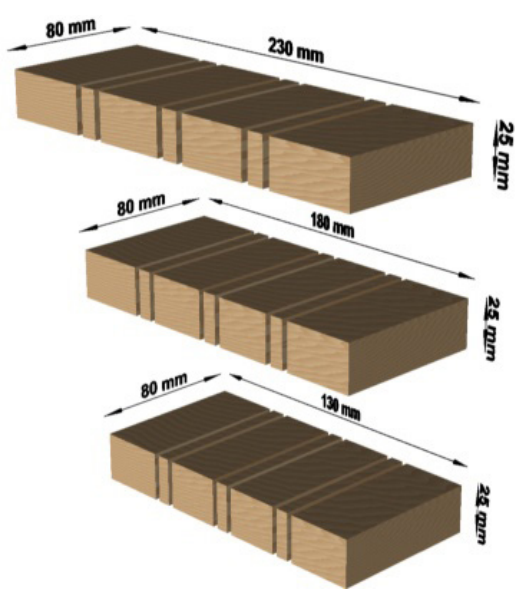

Slika 2: EKSPERIMENT - II; Kontrolne daske i njihove dimenzije.

\section{REZULTATI I DISKUSIJA}

Piljena građa, nakon prvobitnog sušenja prirodnim putem, sušena je u industrijskoj, klasičnoj sušari komornog tipa do nekog finalnog sadržaja vlage, da bi se kasnije dobio gotov proizvod. Polazni sadržaj vlage u drvetu, određen na 30 uzoraka, je bio $(0,4984 \pm 0,0674) \mathrm{kgvl} / \mathrm{kgsm}$. Relativno velika standardna devijacija za sadržaj vlage u polaznom materijalu predstavlja i faktor koji dovodi do problema prilikom sušenja i korišćenja građe [4]. Građa je industrijski sušena vazduhom srednje tempera-ture $35 \pm 1,5^{\circ} \mathrm{C}, 24$ dana, pri brzini vazduha u opsegu od 3 do $5 \mathrm{~m} / \mathrm{s}$. Relativna vlažnost vazduha u komori menjala se u toku rada od oko $85 \%$ (u toku prvih 5 dana), preko $80 \%$ (u toku nerednih 5 dana), uz dalje smanjenje sve do oko $65 \%$ u poslednjim danima sušenja. Automatska regulacija procesa sušenja ostvarena je na osnovu merenja promena sadržaja vlage u drvetu tokom sušenja, pri čemu je vlaga merena elektrovlagomerima. Režim sušenja postavljen je na osnovu prethodnih iskustava i uputstva proizvođača sušnice, vezanog za konkretne uslove sušenja: kvalitet drveta i polaznu vlažnost drveta [6].

\subsection{Ispitivanje rasporeda vlage u drvenoj građi to- kom sušenja (EKSPERIMENT - I)}

Raspored vlage $\mathrm{u}$ kontrolnim daskama dimenzija $230 \times 80 \times 25$ $\mathrm{mm}$ nakon vremena sušenja od $48 \mathrm{~h}$ i $360 \mathrm{~h}$ prikazan je 3D dijagramima na Slici 3. Koordinate $\mathrm{X}$ i $\mathrm{Y}$ ovih dijagrama predstavljaju dužinu i širinu kontrolne daske. Vrednosti X i Y na dijagramu su normalizovane, tj. podeljene sa dužinom, odnosno, širinom daske. Vrednosti sadržaja vlage u svakom polju date su za tačke koje predstavljaju koordinate centra polja. Konturne linije povezuju tačke sa istim sadržajem vlage.

Sa dijagrama se vidi da je u centru daske najveći sadržaj vlage i da se vlaga kreće brže duž X ose u odnosu na kretanje u pravcu Y ose. Količina vode koja izlazi na čela rezane građe uvek je manja od količine vode koja izlazi na ostalim površinama, pošto su čeone površine veoma male u odnosu na ukupnu površinu rezane građe [1]. 


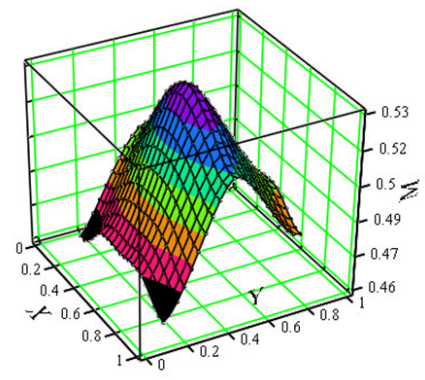

Vreme sušenja $48 \mathrm{~h}$

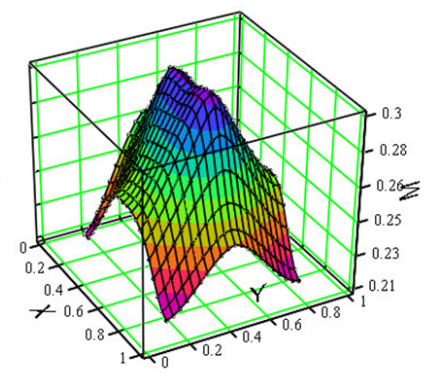

Vreme sušenja $360 \mathrm{~h}$
Slika 3: 3D dijagram rasporeda sadržaja vlage u kontrolnoj dasci dimenzija $230 \times 80 \times 25 \mathrm{~mm}$ nakon vremena sušenja od $48 \mathrm{~h}$ (levo) i $360 \mathrm{~h}$ (desno)

Regresionom analizom, dobijene su zavisnosti sadržaja vlage u funkciji relativnog položaja tačke na dasci, za različita vremena sušenja, što je prikazano u Tabeli 1. Rezultati ovog eksperimenta potvrđuju činjenicu da je difuzija u smeru drvnih vlakanca (longitudinalnom smeru) brža od difuzije u tangencijalnom ili radijalnom smeru [1,5]. U zavisnosti od vrste drveta, difuzija u smeru drvnih vlakanca može biti i 10 do 15 puta brža od difuzije u tangencijalnom ili radijalnom smeru.

Tabela 1. Sadržaj vlage (kgvl/kgsm) u funkciji relativnog položaja tačke na dasci, za različita vremena sušenja. Koordinate $\mathrm{X}$ i Y predstavljaju dužinu i širinu kontrolne daske (normalizovane vrednosti)

\begin{tabular}{|c|c|}
\hline $\begin{array}{c}\text { Vreme } \\
\text { sušenja[h] }\end{array}$ & Zavisnost \\
\hline 24 & $M=0,473+0,044 \cdot X+0,172 \cdot Y-0,034 \cdot X^{2}-0,077 \cdot X \cdot Y-0,135 \cdot Y^{2}$ \\
\hline 48 & $M=0,393+0,105 \cdot X+0,385 \cdot Y-0,111 \cdot X^{2}+0,008 \cdot X \cdot Y-0,355 \cdot Y^{2}$ \\
\hline 120 & $M=0,321+0,168 \cdot X+0,397 \cdot Y-0,191 \cdot X^{2}+0,004 \cdot X \cdot Y-0,395 \cdot Y^{2}$ \\
\hline 168 & $M=0,348-0,004 \cdot X+0,172 \cdot Y-0,017 \cdot X^{2}-0,012 \cdot X \cdot Y-0,161 \cdot Y^{2}$ \\
\hline 192 & $M=0,258+0,207 \cdot X+0,366 \cdot Y-0,223 \cdot X^{2}-0,056 \cdot X \cdot Y-0,328 \cdot Y^{2}$ \\
\hline 288 & $M=0,164+0,314 \cdot X+0,282 \cdot Y-0,258 \cdot X^{2}-0,042 \cdot X \cdot Y-0,268 \cdot Y^{2}$ \\
\hline 312 & $M=0,23+0,064 \cdot X+0,278 \cdot Y-0,146 \cdot X^{2}+0,029 \cdot X \cdot Y-0,298 \cdot Y^{2}$ \\
\hline 336 & $M=0,15+0,235 \cdot X+0,375 \cdot Y-0,245 \cdot X^{2}+0,004 \cdot X \cdot Y-0,373 \cdot Y^{2}$ \\
\hline 360 & $M=0,134+0,225 \cdot X+0,471 \cdot Y-0,26 \cdot X^{2}-0,005 \cdot X \cdot Y-0,451 \cdot Y^{2}$ \\
\hline 576 & $M=0,114+0,245 \cdot X+0,309 \cdot Y-0,259 \cdot X^{2}+0,032 \cdot X \cdot Y-0,297 \cdot Y^{2}$ \\
\hline
\end{tabular}

\subsection{Ispitivanje kinetike sušenja za daske različitih di- menzija (EKSPERIMENT - II)}

Krive sušenja za daske korišćene za (EKSPERIMENT - II) dimenzija $230 \times 80 \times 25 \mathrm{~mm}$ (serija 1), $180 \times 80 \times 25 \mathrm{~mm}$ (serija 2) i $130 \times 80 \times 25 \mathrm{~mm}$ (serija 3 ) prikazane su na Slici 4 .

Krive sušenja predstavljene punim linijama dobijene su matematičkim modelovanjem. Rezultati pokazuju da u ovom slučaju dimenzije dasaka nemaju statistički značajan uticaj na oblik krive, odnosno na brzinu sušenja. Uopšteno rečeno, krive sušenja drveta ne pokazuju linearan trend već brzina sušenja od samog starta sušenja opada. Rezultati ispitivanja kinetike sušenja za daske različitih dimenzija pokazuju da su vrednosti parametara veoma bliske za sve tri ispitivane serije, odnosno veličine dasaka, tj da dužina daske koja se suši nije imala uticaja na brzinu sušenja. Ovi razultati su u skaldu sa očekivanim vrednostima, pošto je iz literature poznato da debljina $\mathrm{i}$ širina daske imaju presudan uticaj na sušenje.

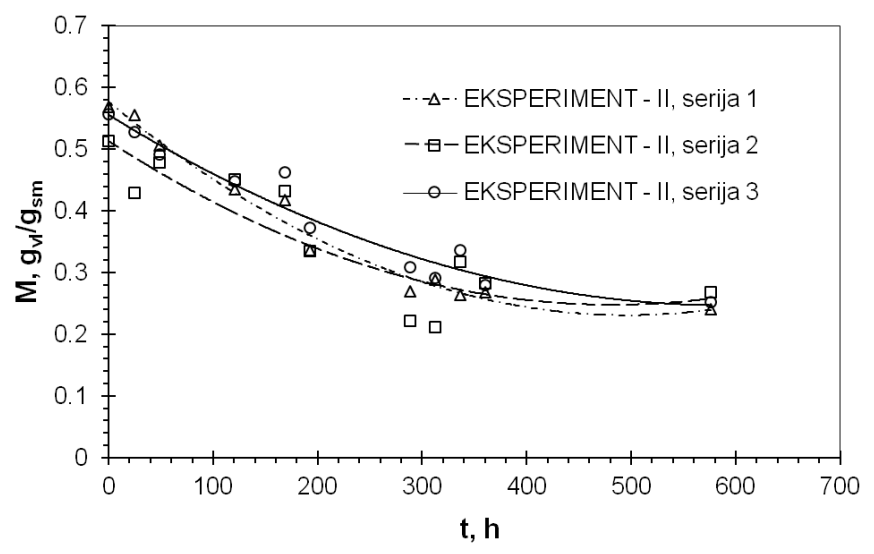

Slika 4: Kriva sušenja za daske iz tri serije EKSPERIMENT II; dimenzije: serija 1: $230 \times 80 \times 25 \mathrm{~mm}$, serija $2: 180 \times 80 \times 25$ $\mathrm{mm}$, serija 3: $130 \times 80 \times 25 \mathrm{~mm}$

Tabela 2. Rezultati modelovanja kinetike sušenja rezane građe u industrijskim uslovima za kontrolne daske rezličitih veličina: vrednosti parametara i vrednosti koeficijenta korelacije R2. EKSPERIMENT - II; dimenzije: serija 1: $230 \times 80 \times 25 \mathrm{~mm}$, serija 2: $180 \times 80 \times 25 \mathrm{~mm}$, serija $3: 130 \times 80 \times 25 \mathrm{~mm}$

\begin{tabular}{c|c|c|c|c|} 
Jednacina & $\begin{array}{c}\text { Naziv } \\
\text { koeficijenta }\end{array}$ & Serija 1 & Serija 2 & Serija 3 \\
\hline \multirow{2}{*}{$(2)$} & $k$ & $2,199 \cdot 10^{-3}, \mathrm{~h}^{-1}$ & $1,772 \cdot 10^{-3}, \mathrm{~h}^{-1}$ & $1,847 \cdot 10^{-3}, \mathrm{~h}^{-1}$ \\
& $R^{2}$ & 0,971 & 0,859 & 0,914 \\
\hline \multirow{2}{*}{$(3)$} & $k_{1}$ & $4,334 \cdot 10^{-3}, \mathrm{~h}^{-1}$ & $3,85 \cdot 10^{-3}, \mathrm{~h}^{-1}$ & $4,244 \cdot 10^{-3}, \mathrm{~h}^{-1}$ \\
& $R^{2}$ & 0,987 & 0,874 & 0,930 \\
\hline & $k_{2}$ & 1,026 & 0,995 & 1,015 \\
$(4)$ & $k_{3}$ & $4,468 \cdot 10^{-3}, \mathrm{~h}^{-1}$ & $3,826 \cdot 10^{-3}, \mathrm{~h}^{-1}$ & $4,322 \cdot 10^{-3}, \mathrm{~h}^{-1}$ \\
& $R^{2}$ & 0,987 & 0,80 & 0,90 \\
\hline & $k_{4}$ & $2,337 \cdot 10^{-3}$ & $6,265 \cdot 10^{-4}$ & $2,721 \cdot 10^{-3}$ \\
$(5)$ & $y$ & 1,114 & 1,333 & 1,082 \\
& $R^{2}$ & 0,984 & 0,851 & 0,905 \\
\hline & $\beta_{0}$ & 0,581 & 0,513 & 0,553 \\
& $\beta_{1}$ & $-1,421 \cdot 10^{-3}, \mathrm{~h}^{-1}$ & $-1,102 \cdot 10^{-3}, \mathrm{~h}^{-1}$ & $-1,151 \cdot 10^{-3}, \mathrm{~h}^{-1}$ \\
& $\beta_{2}$ & $1,441 \cdot 10^{-6}, \mathrm{~h}^{-2}$ & $1,143 \cdot 10^{-6}, \mathrm{~h}^{-2}$ & $1,104 \cdot 10^{-6}, \mathrm{~h}^{-2}$ \\
& $R^{2}$ & 0,991 & 0,89 & 0,93 \\
\hline
\end{tabular}

Krive sušenja fitovane su sa nekoliko empirijskih modela za predviđanje sadržaja vlage, jednačine (2), (3), (4), (5) i (6), a rezultati modelovanja, odnosno, vrednosti parametara koji figurišu u navedenim modelima i vrednosti koeficijenta korelacije R2 prikazani su u Tabeli 2.

Rezultati modelovanja pokazuju da ne postoji statistički značajna razlika u brzinama uklanjanja vlage iz dasaka različitih dimenzija. Takođe, utvrđeno je da nema značajne razlike u nagibima regresionih linija. Procenjena vrednost ravnotežnog sadržaja vlage u jednačini 
3, Mr, iznosi 0,195 kgvl/kgsm. Jednostavan eksponencijalni model (jed. 4) i Page model (jed. 5) dobijeni su pojednostavljenjem matematičkog rešenja drugog Fikovog zakona difuzije, koji ima oblik opštih redova. Prost eksponencijalni model je prvi član opšteg reda koji se dobija kao rešenje modela. On bi po svojoj prirodi trebalo da dosledno prebacuje vrednosti brzine sušenja u početnom stadijumu sušenja i podbacuje vrednosti u kasnijem stepenu sušenja [9]. Rezultati modelovanje pokazuju da Page model (jed. 5) nije značajno poboljšao predviđanje promene relativnog sadržaja vlage sa vremenom u odnosu na jednostavan eksponancijalni model (jed. 4). S obzirom da model jednačina (6) ima najviše parametara $u$ odnosu na sve ostale primenjene modele, za očekivati je bilo da najbolje opisuje eksperimentalno dobijenu promenu sadržaja vlage $\mathrm{u}$ dasci sa vremenom sušenja. Kriva sušenja dasaka korišćenih u ovom radu se, stoga, može opisati polinomom drugog stepena (kvadratnom jednačinom). Na osnovu matematičkog modela krive sušenja (jed. 6) dobijena je diferenciranjem kriva brzine sušenja i to takvog oblika da se može zaključiti da ne postoji period konstantne brzine sušenja, odnosno da brzina sušenja opada u toku procesa. U najboljem slučaju, brzina sušenja bi se mogla opisati sa dva perioda opadajuće brzine sušenja. U toku prvog perioda, brzina sušenja je kontrolisana brzinom konventivnog prenosa toplote. U drugom periodu sušenja, brzina sušenja je kontrolisana difuzijom vezane vode.

Svi ispitani empirijski modeli podjednako uspešno opisuju krivu sušenja za svaku od ispitivanih veličina dasaka. Nešto veće rasipanje eksperimentalnih podataka za seriju 2 EKSPERIMENTA II, uslovilo je manje vrednosti koeficijenata korelacije u odnosu na vrednosti za preostale dve serije.

\section{4}

\section{ZAKLJUČAK}

Polazni sadržaj vlage hrastove rezane građe, određen na 30 uzoraka, je bio oko $0,5 \mathrm{kgvl} / \mathrm{kgsm}$. Relativno velika standardna devijacija za sadržaj vlage u polaznom materijalu, 0,07 kgvl/kgsm predstavlja faktor koji dovodi do problema prilikom sušenja i korišćenja građe. Procenjena vrednost ravnotežnog sadržaja vlage u iznosi 0,195 kgvl $/ \mathrm{kgsm}$. Brzina sušenja opada u toku procesa, odnosno nije uočen period konstantne brzine sušenja. U najboljem slučaju, brzina sušenja bi se mogla opisati sa dva perioda opadajuće brzine sušenja, prvi kontrolisan brzinom konventivnog prenosa toplote i drugi period sušenja kontrolisan difuzijom vezane vode. Uočeno je da je difuzija u smeru drvnih vlakanca (longitudinalnom smeru) brža od difuzije u tangencijalnom ili radijalnom smeru. Dužine dasaka nemaju statistički značajan uticaj na oblik krive, odnosno na brzinu sušenja. Određeni su koeficijenti za pet empirijskih modela primenjenih za matematičko modelovanje kinetike sušenja rezane hrastove građe.

\section{Literatura}

[1] Tomić, B., Sušenje drveta, Zavod za udžbenike i nastavna sredstva, Beograd, SFRJ 1981.

[2] Wengert, E. M., Principles and practice of drying lumber, Lignomat USA, Ltd., USA, 2006.
[3] Kolin, B., Hidrotermička obrada drveta, Jugoslavija public, Beograd, SR Jugoslavija, 2000.

[4] Redman, A., Moisture variation in dried hardwood timber, Project No. PN01.1305, Forest and wood product research and development corporation, Ltd., Victoria, Australia, 2004.

[5] Zink-Sharp, A., Hanna R. B., Moisture distribution and flow during drying wood and fiber, Final Technical report, DE-FC0797ID13537, FINAL report - OSTI.GOV, 2001, https://www.osti.gov/ servlets/purl/789798

[6] INCOMAC, Operation and maintenance instruction, Incomac, Montebelluna, Treviso, Italia, 2004.

[7] INCOMAC, Wood drying systems, Incomac, Montebelluna, Treviso, Italia, 2004. http://www.incomac.it/pdf/en/catalog.pdf at http:// www.incomac.it/prodotti/icd.do

[8] Deomano, E. D. C., Mechanism of flake drying and its correlation of quality, Ph.D. Thesis, Faculty of Virginia Polytechnic Institute and State University, Blacksburg, Virginia, USA, 2001. scholar.lib. vt.edu/theses/available/etd-07302001-100811/unrestricted/flake_ drying.pdf

[9] Sridhar, D., Madhu G. M., Drying kinetics and mathematical modeling of Casuarina Equisetifolia wood chips at various temperatures, Periodica Politechnica Chemical Engineering, 59 (2015), 4, pp. 288-295. DOI:10.3311/PPch.7855

[10] Laytner, F., Fundamentals and technology of wafer drying. Ph.D. Thesis. University of British Columbia, Vancouver, Canada, 1989.

\section{Autor}

Branislava G. NIKOLOVSKI

Univerzitet u Novom Sadu

Tehnološki fakultet Novi Sad

barjakb@uns.ac.rs

\section{Biljana M. MILJKOVIĆ \\ Univerzitet u Novom Sadu \\ Fakultet tehničkih nauka Novi Sad}

Sanja A. JAGODIĆ1

Univerzitet u Novom Sadu

Tehnološki fakultet Novi Sad

Momčilo Đ. SPASOJEVIĆ

Univerzitet u Novom Sadu

Fakultet tehničkih nauka Novi Sad

Milana N. SOVILJ

Univerzitet u Novom Sadu

Tehnološki fakultet Novi Sad 